\title{
Acquainting Veterinary Students with Careers in the Pharmaceutical Industry
}

\author{
Douglas D. McGregor - David R. Fraser michelle L. Haven Gerard J. Hickey
}

\begin{abstract}
Careers in the pharmaceutical industry were revealed in modules facilitated by senior scientists from companies that sponsor the Cornell Leadership Program for Veterinary Students. One module was structured as a series of interviews for different positions in industry, the other as a competition between hypothetical companies created by students. The interview-based module stimulated wide-ranging discussion of the activities and responsibilities of veterinarians employed in a discoveryintensive pharmaceutical firm and of the characteristics such companies seek in prospective employees, from both professional and personal perspectives. The second module explored the drug discovery and development process from the perspective of animal-health companies that are competitors in the market for animal health care products. The exercise provided insights into the manner in which companies discover new chemical entities, screen candidate drugs, allocate resources, and pursue the development of products through testing, licensing, and distribution.
\end{abstract}

\section{BACKGROUND}

Cornell University hosts an annual Leadership Program for Veterinary Students. The program targets students who have the ability and commitment to broadly influence their profession. The initiative combines independent, faculty-guided research; vocational counseling; and group learning modules calculated to develop creativity, critical thinking, effective communication, and teamwork skills. All are student-directed exercises that encourage broad participation and enable students to participate actively in their own education. ${ }^{1}$

Two of the group learning modules are subjects of this report. Both highlight career opportunities for veterinary graduates in the pharmaceutical industry. In the following narrative we comment on the evolution of the modules, their current structure, and their perceived value in informing students about employment opportunities in mature, discovery-based firms whose principal purposes are to develop and market products for the treatment or prevention of animal diseases.

\section{CAREERS IN INDUSTRY}

The typical veterinary curriculum leaves little room for students to acquire knowledge about discovery-based careers. Nowhere is that deficiency more conspicuous than in careers in business, and the pharmaceutical industry in particular. An effort to address the problem within the context of the leadership program began in 1990, the first year the program was offered. Scientists from Merck were invited to address the students. These visitors explained the range of employment opportunities for veterinarians in a major research-oriented pharmaceutical firm; they contrasted the activities of industrial scientists with the responsibilities incumbent on academic faculty. In addition to the presentations at Cornell, participating scholars visited the research facilities of Merck in Rahway, New Jersey, and the company's nearby Branchburg farm.
The presentations were well received, but their passive format limited the depth of understanding that students were able to gain from the experience. Participation was limited to questions and occasional comments from students who had work experience in an industrial setting. The field visit to Rahway and to Merck's research farm provided greater scope for student involvement; but this significant benefit was offset by a time commitment that could not be readily accommodated within the already busy schedule of the 10-week program.

Beginning in 2004, the "Merck module" was modified with a view to engaging students more actively. The revised event is structured as a series of mock interviews in which students are quizzed about their motivation and aptitude for veterinary staff positions. In advance of the meeting, and as a framework for discussion, students are given three typical and different position descriptions and the dossiers of three hypothetical candidates. Resource materials consisting of scientific articles based on plausible experiences of the prospective applicants and information about the responsibilities and expectations of successful candidates are included in a program workbook. A videodisc recording of events connected with the previous year's program is provided for the students' convenience and to illustrate how the module is structured.

The students divide themselves into three groups, each representing a candidate for one of the three positions. The individual groups are obliged to submit a letter of application for the position they select. The letters are reviewed by three staff scientists or service specialists at Merck. On the day of the meeting, the facilitators interview the groups sequentially. Students not involved in this phase of the proceedings observe the performance of their fellow students and reflect on the nature of the facilitators' questions until they in turn assume the role of "applicant."

The module has achieved its intended purpose. Much of the information that emerged in the passive presentations 
of earlier years is now revealed in more active exchanges between students and facilitators. But the interviews have additional advantages over the original model. First, they are riveting experiences, in the sense that students cannot anticipate what questions they will be asked or when their comments will be solicited. Second, the new format ensures universal participation, since each student is obliged to respond to facilitator questions and to raise questions of his or her own. Third, and arguably most importantly, the revised structure provides students with practical experience of the interview processes-experience that will serve them well later in their careers.

\section{DRUG DESIGN AND DEVELOPMENT}

An entirely different approach was used in the second exercise, which grew out of an in-house training program at Pfizer Animal Health. This module illustrates opportunities and challenges connected with the discovery, development, and marketing of pharmaceuticals. The objective is to acquaint students with the drug-discovery process. Prominence is given to how candidate drugs are selected; how testing procedures are conducted; the requirements for licensing products, and practical matters connected with the marketing and use of pharmaceuticals and biologicals. All focus on striving for efficient processes and working within a budget in a competitive environment. Special emphasis is placed on career opportunities for veterinarians at each stage in the process.

The Pfizer module is organized as a competition. In preparing for it, the students divide themselves into three teams, each representing a pharmaceutical company attempting to launch a product for the treatment of osteoarthritis in dogs. Each team chooses a company name and assigns its members to groups concerned with the biology and chemistry of drugs, drug safety and metabolism, manufacturing, testing of drugs both in vitro and in patients, licensing of products, marketing, and the provision of technical services to practitioners and their clients. In advance of the formal meeting, each team prepares a one-page outline for the development and marketing of their product. The plans are reviewed by three facilitators at Pfizer, who comment on the teams' strategies and draw attention to issues requiring clarification or further explanation.

On the day of the module, the teams present their plans to the three facilitators and the students at large. Questions arising during the presentations are considered privately by the individual groups during a recess. Thereafter, the groups reassemble to present their revised plans or defend their initial approaches. At the conclusion of the meeting, the facilitators comment on the three plans and on principles and practices that drive the drug-discovery process. These include, but are not limited to, resource allocation and scientific, economic, and ethical issues connected with the development and marketing of pharmaceuticals.

The drug-discovery module has not been modified significantly during the seven years that it has been an important feature of the leadership program. Students find the exercise informative and challenging. Their enthusiasm is reflected in the creativity they demonstrate in devising a product-development plan and defending their individual strategies. From a learning perspective, the value of the module lies in its capacity to illustrate careers for veterinarians in a discovery-based pharmaceutical firm.

\section{DISCUSSION}

Industry offers a wide range of employment opportunities for veterinarians, but remarkably few veterinary graduates choose that career option. ${ }^{2,3}$ By virtue of their training in comparative biology and animal diseases, veterinarians are uniquely qualified to manage large colonies of experimental animals required for basic biomedical research and the testing and licensing of pharmaceuticals. Moreover, veterinarians with advanced training in pathology or clinical studies are well prepared to function as specialists in comparative pathology, toxicology, and drug evaluation. These and other positions in the pharmaceutical industry offer attractive financial benefits and sensitivity to the work-life balance needs of employees and their families. Yet remarkably few veterinary graduates follow these career paths. Data published by the American Veterinary Medical Association indicate that less than $2.4 \%$ of US veterinary graduates realize careers in commercial enterprises. ${ }^{4}$ However, those who do choose this option readily find employment in major pharmaceutical firms, service companies, and discovery-based organizations whose origins can be traced to the remarkable advances made in biotechnology during the past several decades.

The foregoing considerations raise the question of why veterinarians are not attracted in larger numbers to these diverse and professionally rewarding occupations. One possibility is that the opportunities are not often portrayed to veterinary students in a realistic and compelling manner. A notable exception is the curriculum at Virginia-Maryland Regional College of Veterinary Medicine (VMRC), which has adopted a flexible course that enables students to tailor their education to their vocational interests and career aspirations. ${ }^{5}$ The Public/Corporate Veterinary Medicine track at VMRC focuses on aspects of veterinary science that are especially relevant to individuals aspiring to a career in industry. Other colleges may provide similar information through course electives and vocational options. ${ }^{6}$ These experiences emphasize skills that are important for industrial scientists and veterinary service specialists to acquire. Nevertheless, it could be argued that exercises presented from an academic perspective may not capture the "corporate culture" as effectively as facilitatoraided modules conducted by scientists who have industrial experience and presently occupy positions well suited to veterinary graduates.

However that may be, the desire to portray industrial careers for veterinarians in a more informative manner provided the impetus for developing the two modules reported here. Both were organized by senior scientists at pharmaceutical companies who had personal experience and supervisory responsibilities for individuals employed in the discovery-based vocations and service positions to which veterinary graduates are naturally attracted. 
The facilitators also could speak with conviction to the advantages and limitations of careers pursued in an industry setting.

The module designed by scientists at Merck compares discovery-based careers in a major pharmaceutical firm with the activities pursued by academic faculty. Initially, the subject was addressed passively, in a lecture format followed by an informal period of questions and discussion. The presentations were informative, but the discussion was uneven and usually dominated by a few members of the audience. In an effort to involve students more actively, the authors restructured the module as a series of interviews. Students within individual groups are now asked questions regarding their motivation and qualifications for the positions for which they have applied. The facilitators not only answer the questions but explain how the discovery process is managed in a commercial enterprise. In the course of the exchanges, the facilitators also emphasize the characteristics that a corporation seeks in potential employees. These include, but are not limited to, knowledge, creativity, a good work ethic, interpersonal skills, and the capacity of employees to work effectively as members of a team.

Halfway through the individual interviews, the roles of interrogator and responder are reversed, thereby enabling students to explore different aspects of industrial careers. Students are eager to learn about job security, the compensation they can expect, and the capacity of employees to remain purposefully involved in projects as products move through development, through the approval process, and into the marketplace.

The interview model has several advantages over the original presentation format. First, students have the opportunity to consider relevant materials prior to the meeting and to organize their thoughts on the topics to be discussed. The interviews are also successful in engaging the entire student group. Finally, students gain practical experience in preparing themselves for an interview. Notable in this connection is the advice facilitators offer for constructing an application letter. Emphasis is placed on how individuals should illustrate their qualifications for employment and their knowledge of the company concerned.

The second module was modeled on a program developed for Pfizer employees. The exercise encourages creativity and effective communication while simultaneously promoting the development of teamwork skills. The Pfizer module reveals practical aspects of drug development that may be infrequently addressed in the conventional veterinary curriculum. Topics include resource allocation within a pharmaceutical company; considerations that bear upon the selection of candidate drugs; the influence of competitive pressures; and outcomes that lead to the advancement or termination of a project. The module illustrates the importance of teamwork and flexibility on the part of employees; requirements that must be satisfied in licensing drugs and biologicals; and strategies for the management of products in the marketplace. It also inspires students to explore existing knowledge about a major veterinary disease problem and to face the challenge of designing an effective therapeutic agent.

\section{SUMMARY}

The Cornell Leadership Program for Veterinary Students gives prominence to two student-directed modules that highlight careers in the pharmaceutical industry. The modules were developed jointly by the program organizers and senior scientists from two corporate sponsors of the program, Merck and Pfizer. The exercises use different formats, but both provide insights into the operations of discovery-based companies while highlighting the skills and personal characteristics that such companies seek in prospective employees. Students find the modules thought-provoking and welcome the opportunity they afford to establish useful contacts with scientists in the participating companies.

\section{ACKNOWLEDGMENTS}

The Cornell Leadership Program is presently funded by grant AI 07227 from the National Institutes of Health and by fellowship awards form Merck \& Co. Foundation, Pfizer, the Albert C. Bostwick Foundation, and the Wellcome Trust.

\section{REFERENCES}

1 McGregor DD, Fraser DR. Promoting science-based careers through student-directed learning. J Vet Med Educ 33:294-298, 2006.

2 Royal College of Veterinary Surgeons [RCVS]. A Survey of Employment in the U.K. Veterinary Profession in 2002. London: RCVS, 2002 p8.

3 Employment and age of male and female AVMA members 2003. J Am Vet Med Assoc 225:876-877, 2004.

4 American Veterinary Medical Association [AVMA]. AVMA Membership Directory and Resource Manual. Schaumburg, IL: AVMA, 2005 p24.

5 Eyre P. Veterinary education with career emphasis: a partnership with private, public and corporate veterinary practice. J Am Vet Med Assoc 200:311-315, 1992.

6 College of Veterinary Medicine, Western University of Health Sciences. Curriculum <http://www.westernu.edu/ veterinary/curriculum.xml>. Accessed 12/18/06. Western University of Health Sciences, 2006.

\section{AUTHOR INFORMATION}

Douglas D. McGregor, MD, is Professor of Immunology in the College of Veterinary Medicine at Cornell University, 416 Hanshaw Road, Ithaca, NY 14850 USA.

E-mail: ddm7@cornell.edu. He is Director of the Cornell Leadership Program for Veterinary Students.

David R. Fraser, PhD, is Professor of Animal Science in the Faculty of Veterinary Sciences, University of Sydney, NSW 2006, Sydney, Australia. E-mail: davidf@vetsci.usyd.edu.au. He is Co-Director of the Leadership Program. 
Michelle L. Haven, DVM, PhD, is Executive Director, Global Discovery, Animal Health, Pfizer Inc., 7000 Portage Road, RIC-190-NE740, Kalamazoo, MI 49001 USA.

E-mail: michelle.i.haven@pfizer.com.

Gerard J. Hickey, MBV, PhD, is Senior Director, Pharmacology and Animal Health, Merck Research Laboratories, PO Box
2000 - RY80Y-250, 126 E. Lincoln Avenue, Rahway, NJ 07065 USA. E-mail: gerry_hickey@merck.com.

Address correspondence to Dr. Douglas McGregor, College of Veterinary Medicine, S2056 Schurman Hall, Cornell University, 416 Hanshaw Road, Ithaca, NY 14850 USA.

E-mail: ddm7@cornell.edu.

\title{
AMEE 2007 25-29 August: Trondheim, Norway Trondheim Spektrum Conference Centre and Norwegian University of Science and Technology (NTNU)
}

The AMEE conference is the largest annual international event focusing entirely on medical and healthcare professions education. The conference provides an opportunity to network with others with similar interests, to hear and discuss the views of acknowledged experts and is relevant to teachers, researchers, educationalists, deans, administrators and students. The continuum of education is covered, from undergraduate or basic training, through postgraduate or specialist training to CPD/CME.

\section{Conference highlights:}

Pre-Conference Symposium on Students as a (valuable) resource: 25-26 August: a Symposium organised in collaboration with IFMSA that will focus on the medical student and the relationship between students, teachers and the faculty;

Pre-conference Workshops: $25-26$ August: interactive workshops on a wide range of topics held at Norwegian University of Science \& Technology (NTNU); Conference sessions: 27-29 August: includes plenaries, short communications, poster presentations, conference workshops and fringe sessions; Exhibition of commercial products \& services and academic projects.

\section{Courses at AMEE 2007: Essential Skills in Medical Education (ESME) Course: another opportunity to take part in the AMEE accredited teaching skills course aimed both at those new to teaching or those assuming additional teaching responsibilities who wish to gain a teaching qualifi cation;}

\section{Fundamentals of Assessment in Medical Education (FAME): a new course offered in collaboration with the National Board of Medical Examiners and FAIMER, covering the basic principles of assessment;}

\author{
Research Essential Skills in Medical \\ Education (RESME): another new AMEE \\ course to meet the demand for basic skills \\ in carrying out research in medical \\ education.
}

\section{Register online by 31st May, pay by credit card and take advantage of reduced registration fees www.amee.org}

\author{
Association for Medical Education in Europe (AMEE) \\ Tel + 44(0) 1382381953 Fax: + 44 (0)1382 381987 \\ Email: amee@dundee.ac.uk; http://www.amee.org
}

